\title{
STUDI BEBAN KERJA DAN STRESS KERJA BERDAMPAK BURNOUT PADA PEKERJA PELAUT BERKEBANGSAAN INDONESIA
}

\author{
Rauly Sijabat \\ Universitas PGRI Semarang \\ e-mail : raulysijabat@upgris.ac.id \\ Renny Hermawati \\ Universitas Maritim AMNI Semarang \\ e-mail : renny.hermawati@unimar-amni.ac.id
}

\begin{abstract}
ABSTRAK
Burnout merupakan epidemi yang melanda dunia kerja. Burnout yang dialami oleh pekerja dapat berakibat buruk baik bagi pekerja itu sendiri maupun bagi organisasi. Bagi pekerja, burnout dapat menyebabkan hilangnya tujuan dan ketidakmampuan memenuhi kebutuhan dalam bekerja. Bagi organisasi,burnout dapat menyebabkan menurunnya frekuensi kehadiran, produktivitas, kinerja hingga meningkatnya turnover. Kajian empiris mengenai faktor yang menjelaskan burnout dengan pendekatan beban kerja dan stress kerja memberikan hasil yang belum konklusif. Selain itu, bagi perusahaan yang bergerak di bidang jasa atau pelayanan, memiliki risiko terjadinya burnout yang lebih tinggi. Termasuk di dalamnya pekerja pelaut yang menjadi bagian dari industry jasa pelayaran. Berdasarkan fenomena empiris dan teoritis tersebut, penelitian ini bertujuan untuk menguji secara empiris model yang dikembangkan dalam penelitian dan pengaruh beban kerja dan stress kerja dalam menjelaskan terjadinya burnout pada pekerja pelaut.
\end{abstract}

Untuk memenuhi tujuan penelitian, diperlukan data kuantitatif mengenai beban kerja, stress kerja dan burnout. Data-data tersebut diperoleh dari responden penelitian, yaitu pekerja pelaut Indonesia melalui kegiatan wawancara dengan menggunakan kuesioner. Data yang diperoleh menjadi data dasar untuk menguji model penelitian dan pengaruh antar variabel yang dilakukan dengan pendekatan Structural Equation Modeling (SEM).

Berdasarkan hasil pengujian statistik yang dilakukan dengan pendekatan SEM dapat diketahui bahwa model empiris yang dikembangkan dalam penelitian ini adalah model yang fit, artinya dapat mnejelaskan fenomena burnout pada populasi yang diestimasi dengan menggunakan data sampel. Sedangkan dari hasil pengujian pengaruh antar variabel diperoleh temuan bahwa beban kerja secara statistik terbukti berpengaruh positif signifikan terhadap stress kerja serta beban kerja dan stress kerja secara statistik terbukti berpengaruh positif signifikan terhadap burnout.

Kata kunci : Beban kerja, Stress kerja, Burnout

\begin{abstract}
Burnout is an epidemic that hit the world of work. Burnout experienced by workers can be bad for both the workers themselves and for the organization. For workers, burnout can lead to loss of purpose and inability to meet work needs. For organizations, burnout can lead to decreased attendance, productivity, performance and increased turnover. Empirical studies on the factors that explain burnout with the workload and work stress approach give inconclusive results. In addition, companies engaged in services or services have a higher risk of burnout. This includes seafarers who are part of the shipping service industry. Based on these empirical and theoretical phenomena, this study aims to empirically test the model developed in research and the effect of workload and work stress in explaining burnout among seafarers.
\end{abstract}

To meet the research objectives, quantitative data are needed regarding workload, work stress and burnout. These data were obtained from research respondents, namely Indonesian seafaring workers through interviews using questionnaires. The data obtained became the basic data to test the research model and the influence between variables using the Structural Equation Modeling (SEM) approach. 
Based on the results of statistical tests carried out with the SEM approach, it can be seen that the empirical model developed in this study is a fit model, meaning that it can explain the burnout phenomenon in the population estimated using sample data. Meanwhile, from the results of testing the influence between variables, it was found that workload was statistically proven to have a significant positive effect on work stress and workload and work stress were statistically proven to have a significant positive effect on burnout.

Keywords : Workload, Work stress, Burnout 


\section{Pendahuluan}

Burnout menyebabkan seseorang tidak memiliki tujuan dan tidak mampu memenuhi kebutuhan dalam bekerja. Pekerja yang mengalami burnout menjadi berkurang energi dan ketertarikannya pada pekerjaan (Rajan et al., 2015). Mereka mengalami kelelahan emosional, apatis, depresi, mudah tersinggung, dan merasa bosan. Adapun ciri-ciri seseorang yang mengalami burnout seperti sakit fisik berupa sakit kepala, demam, sakit punggung, tegang pada otot leher dan bahu, sering flu, susah tidur, dan rasa letih yang kronis (Dita dan Muryantinah, 2014). Kelelahan emosi berupa rasa bosan, mudah tersinggung, sinisme, suka marah, gelisah, putus asa, sedih, tertekan, tidak berdaya. Profesi di bidang pelayanan merupakan profesi yang dianggap memiliki tingkat stres yang lebih tinggi dibandingkan dengan pegawai yang bekerja dibidang lainnya. Hasil penelitian yang dilakukan oleh Schaufeli (dalam Eviaty, 2005) menunjukkan profesi seseorang di bidang jasa menepati urutan pertama yang paling banyak mengalami burnout, yaitu sekitar $43 \%$.

Pelaut sebagai salah satu pekerja di bidang pelayanan yang memiliki resiko tinggi pada terjadinya burnout. Pekerjaan yang dilakukan pelaut di atas kapal menurut Fillhumaan, Nurcholis \& Nurahaju (2019) meliputi menjalankan mesin kapal, menjalankan alat-alat navigasi di atas kapal, bahkan juga menjaga stabilitas kepastian bekerjanya mesin-mesin kapal dengan baik selama melakukan perjalanan laut. Pada kontrak kerja serta perjalanan laut yang panjang maka tugas dan tanggung jawab atas pekerjaan-pekerjaan tersebut cenderung meningkat. Peningkatan tugas dan tanggung jawab pekerjaan tersebut yang memicu terjadinya burnout pada pekerja pelaut Indonesia.

Tingginya burnout, salah satunya disebabkan oleh beban kerja. Hal ini dapat diketahui dari penelitian Atmaja dan Suana (2019), Romadhoni, Asmony dan Suryatni (2015), Pradana, Kristanto dan Hidayat (2017), dan Hardiani (2020) yang menunjukkan bahwa beban kerja dapat mempengaruhi burnout. Arie (2015) menyatakan beban kerja sebagai persepsi pekerja mengenai sekumpulan kegiatan yang harus diselesaikan dalam batas waktu tertentu baik berupa beban kerja fisik maupun psikologis. Beban kerja yang berlebihan bisa meliputi jam kerja, tanggung jawab yang harus dipikul, pekerjaan rutin dan yang bukan rutin, dan pekerjaan administrasi lainnya yang melampaui kapasitas dan kemampuan individu. Di samping itu, beban kerja yang berlebihan dapat mencakup segi kuantitatif yang berupa jumlah pekerjaan dan kualitatif yaitu tingkat kesulitan pekerjaan tersebut yang harus ditangani (Melati dan Surya, 2015). Dengan beban kerja yang berlebihan menyebabkan pegawai berpotensi merasakan adanya ketegangan emosional sehingga dapat mengarahkan perilaku untuk menarik diri secara psikologis dan menghindari diri untuk terlibat (Pines, 1981) dalam Ari dan Dovi (2014).

Faktor role stress (stres kerja) salah satu penyebab terjadinya kejenuhan kerja (burnout) pada karyawan. Greenhaus dan Beutell (2005) dalam Johana et al. (2007) mendefinisikan stres kerja adalah respon individu terhadap keadaan-keadaan dan peristiwa- peristiwa yang mengancam dan menekan individu serta mengurangi kemampuan-kemampuan mereka untuk menghadapinya. Peran stres kerja didefinisikan sebagai kejadian simultan dari dua atau lebih bentuk tekanan pada tempat kerja, dimana pemenuhan dari satu peran membuat pemenuhan terhadap peran lainnya yang lebih sulit untuk dilaksanakan (Sarah et al., 2015). Artinya apabila karyawan mengalami stres ditempat kerja, di saat itu seseorang karyawan dalam melaksanakan satu peran tertentu akan merasa kesulitan untuk memenuhi harapan peran yang lain (Syed, 2014). Peran stres kerja ini cenderung makin meningkat ketika tuntutan beban pekerjaan sebagai tanggung jawab yang harus dilaksanakan. Oleh karena itu, tingkat stres kerja setiap orang cenderung berbeda terkait beban pekerjaan yang dirasakan dan peran yang dialaminya. Tingginya stres yang harus di hadapi pegawai rentan terhadap munculnya gejala-gejala burnout (Berry dalam Eka, 2015).

Tabel 1. Pemetaan Research Gap

\begin{tabular}{lll}
\hline $\begin{array}{c}\text { Pengaruh antar } \\
\text { Variabel }\end{array}$ & \multicolumn{1}{c}{ Sumber Penelitian } & \multicolumn{1}{c}{ Temuan } \\
\hline Pengaruh beban & Atmaja, I Gede Indra Wira \& I Wayan Suana & Beban kerja berpengaruh \\
kerja terhadap & (2019), Romadhoni, Lalu Ciptadi., Thatok Asmony & positif signifikan terhadap \\
burnout & $\begin{array}{l}\text { \& Mukmin Suryatni (2015), Pradana, Bimba Ario., } \\
\text { burnout }\end{array}$ & \\
& $\begin{array}{l}\text { Rudi Suryo Kristanto \& Dwi Suryanto Hidayat } \\
\text { (2017), Hardiani, Wenefrida Ardhian Ayu (2020) }\end{array}$ & \\
\cline { 2 - 3 }
\end{tabular}




\begin{tabular}{|c|c|c|}
\hline & Indilusiantari, Vera \& Inggit Meliana A (2015) & $\begin{array}{l}\text { Beban kerja berpengaruh } \\
\text { positif tidak } \begin{array}{r}\text { signifikan } \\
\text { terhadap burnout }\end{array}\end{array}$ \\
\hline \multirow[t]{3}{*}{$\begin{array}{l}\text { Pengaruh } \begin{array}{r}\text { stress } \\
\text { kerja terhadap } \\
\text { burnout }\end{array} \\
\end{array}$} & $\begin{array}{l}\text { Satriyo, Moch \& Survival (2014), Zeinalpour, } \\
\text { Hamid et al (2014) }\end{array}$ & $\begin{array}{l}\text { Sress kerja berpengaruh } \\
\text { positif signifikan terhadap } \\
\text { burnout }\end{array}$ \\
\hline & $\begin{array}{l}\text { Ibrahim, Isra' Dewi Kuntary., Thatok Asmony \& } \\
\text { Siti Nurmayanti (2017) }\end{array}$ & $\begin{array}{l}\text { Sress kerja berpengaruh } \\
\text { positif tidak } \begin{aligned} \text { signifikan } \\
\text { terhadap burnout }\end{aligned}\end{array}$ \\
\hline & Hera, Rasyidin \& Hasmin (2016) & $\begin{array}{ll}\text { Stress kerja berpengaruh } \\
\text { positif } \\
\text { kignififikan terhadap }\end{array}$ \\
\hline \multirow[t]{2}{*}{$\begin{array}{l}\text { Pengaruh beban } \\
\text { kerja terhadap } \\
\text { stress kerja }\end{array}$} & $\begin{array}{l}\text { Yo, Putu Melati Purbaningrat dan Ida Bagus Ketut } \\
\text { Surya (2015), Kusuma, Aster Andriani dan Yoyok } \\
\text { Soesatyo (2014), Hatmawan, Aglis Andhita (2015), } \\
\text { Rizky, Denizia \& Tri Wulida Afrianty (2018) }\end{array}$ & $\begin{array}{l}\text { Beban kerja berpengaruh } \\
\text { positif signifikan terhadap } \\
\text { stress kerja }\end{array}$ \\
\hline & Nafs, Tazkiatun (2020) & $\begin{array}{l}\text { Beban kerja berpengaruh } \\
\text { positif tidak signifikan } \\
\text { terhadap stress kerja }\end{array}$ \\
\hline
\end{tabular}

Sumber: Disarikan dari Berbagai Jurnal untuk Penelitian ini, 2020

\section{Pengembangan Hipotesis}

\section{Pengaruh Beban Kerja terhadap Stress Kerja}

Ketika karyawan bekerja pada suatu perusahaan maka karyawan tersebut akan melakukan serangkaian tanggung jawab pekerjaan sesuai dengan job description dan jabatan yang di embannya tak terkecuali pekerja pelaut Indonesia. Seringkali pekerjaan yang dilakukan tersebut melebihi apa yang sudah tertera dalam job description-nya yang kemudian direspon sebagai beban kerja. Beban kerja yang terus menerus yang dialami ini akan menimbulkan stress kerja.

Tabel 2. Studi Terdahulu Mengenai Pengaruh Beban Kerja terhadap Stres Kerja

\begin{tabular}{lll}
\hline \multicolumn{1}{c}{ Sumber Penelitian } & \multicolumn{1}{c}{ Variabel Penelitian } & \multicolumn{2}{c}{ Hasil Penelitian } \\
\hline Yo, Putu Melati Purbaningrat dan & Variabel Bebas: & \multicolumn{1}{c}{ Beban kerja berpengaruh } \\
signifikan positif terhadap \\
stress kerja
\end{tabular}


Berdasarkan uraian di atas maka dikembangkan hipotesis berikut:

H1: Beban kerja berpengaruh positif terhadap stress kerja

\section{Pengaruh Beban Kerja terhadap Burnout}

Fajriani dan Septiari (2015) dalam publikasinya menyampaikan bahwa terdapat dua faktor yang dipandang mempengaruhi munculnya bournout, yaitu: (1) Faktor eksternal merupakan kondisi kerja, yang meliputi lingkungan kerja psikologis yang kurang baik, kurangnya kesempatan untuk promosi, imbalan yang diberikan tidak mencukupi, kurangnya dukungan sosial dari atasan, tuntutan pekerjaan, pekerjaan yang monoton, dan (2) Faktor internal meliputi usia, jenis kelamin, harga diri, tingkat pendidikan, masa kerja dan karakteristik kepribadian. Jadi beban kerja yang diteliti dalam penelitian ini adalah faktor eksternal yang berasal dari kondisi kerja yang dapat menimbulkan burnout pada pegawai.

Menurut Bolino dan Turnley (2005) menyatakan bahwa beban kerja terjadi karena seseorang karyawan mempunyai terlalu banyak pekerjaan yang harus dikerjakan dibawah tekanan jadwal waktu yang sangat ketat dan tidak sesuai dengan kemampuan. Ketika terlalu banyak pekerjaan yang harus dikerjakan menyebabkan kelelahan fisik dan mental, bahkan kejenuhan dan stres akibat beban pekerjaan, ditambah lagi dengan perasaan bahwa keahlian yang dimiliki tidak memenuhi tuntutan tugas, hal tersebut yang nantinya akan memicu burnout. Seperti pernyataan Virick dan Casper (2007) bahwa beban kerja menyebabkan tingginya kelelahan fisik dan psikologis. Penelitian yang dilakukan oleh Prijayanti (2015) tentang pengaruh beban kerja dan dukungan sosial terhadap burnout menunjukkan bahwa adanya pengaruh signifikan beban kerja terhadap burnout.

Tabel 3. Studi Terdahulu Mengenai Pengaruh Beban Kerja terhadap Burnout

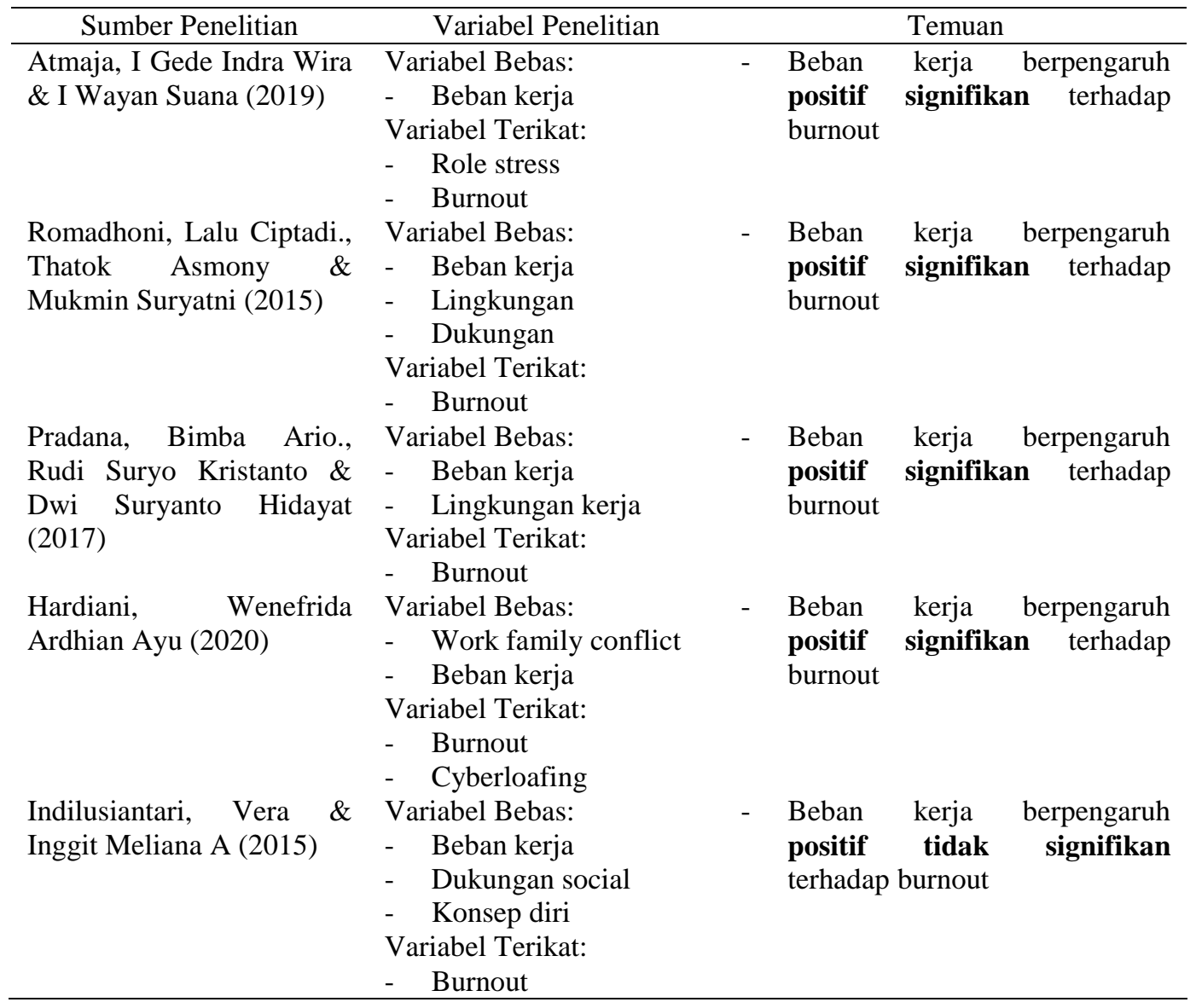


Berdasarkan uraian di atas maka dikembangkan hipotesis berikut:

$\mathrm{H} 2$ : Beban kerja berpengaruh positif terhadap burnout

\section{Pengaruh Stress Kerja terhadap Burnout}

Burnout merupakan bagian dari stres (Luthans, 2005). Burnout merupakan kelelahan fisik, mental, dan emosional yang terjadi karena stres yang diderita dalam jangka waktu yang lama dan melibatkan emosional yang tinggi (Leither dan Maslach, 2005). Kreitner dan Kinicki (2010) menyatakan bahwa burnout merupakan akibat dari stres yang dialami individu dalam jangka waktu yang lama dan dengan intensitas yang cukup sering, ditandai dengan kelelahan fisik, mental, dan emosional, serta rendahnya pengahargaan terhadap diri sendiri yang mengakibatkan individu merasa terpisah dari lingkungannya.

Temuan pada penelitian yang dilakukan oleh Romadhoni, Asmony dan Suryatni (2015) menyatakan bahwa stres pada individu di tempat kerja yang berlangsung secara terus menerus akan menyebabkan kelelahan emosional dan motivasi rendah sehingga akan mempengaruhi timbulnya burnout. Seperti yang dinyatakan Hardiyanti (2013) bahwa burnout merupakan epidemi yang melanda dunia kerja, memperlihatkan bagaimana kondisi emosional individu yang merasa letih serta jenuh secara mental dikarenakan tuntutan dan tekanan pekerjaan yang tinggi.

Burnout dapat terjadi kepada seorang karyawan ketika kondisi emosionalnya tidak stabil dan stres yang dialami karyawan tersebut berkepanjangan (Satriyo dan Survival, 2014). Karyawan tersebut menjadi tidak memiliki minat dan ketertarikan terhadap pekerjaan yang dilakukannya. Zeinalpour et al (2014) menjelaskan berdasarkan hasil temuan studinya bahwa penyebab terjadinya burnout pada karyawan adalah karena tekanan atau beban pekerjaan yang besar, sehingga karyawan merasa tidak senang dan nyaman dalam menyelesaikan pekerjaannya.

Tabel 4. Studi Terdahulu Mengenai Pengaruh Stress Kerja terhadap Burnout

\begin{tabular}{|c|c|c|}
\hline Sumber Penelitian & Variabel Bebas & Temuan \\
\hline $\begin{array}{l}\text { Satriyo, Moch \& Survival } \\
\text { (2014) }\end{array}$ & \begin{tabular}{l}
\multicolumn{2}{l}{ Variabel Bebas: } \\
$-\quad$ Stress kerja \\
Variabel Terikat: \\
$-\quad$ Burnout \\
$-\quad$ Kinerja karyawan
\end{tabular} & $\begin{array}{l}\text { - Sress kerja berpengaruh positif signifikan } \\
\text { terhadap burnout }\end{array}$ \\
\hline $\begin{array}{l}\text { Zeinalpour, Hamid et al } \\
\text { (2014) }\end{array}$ & $\begin{array}{l}\text { Variabel Bebas: } \\
-\quad \text { Stress kerja } \\
-\quad \text { Lingkungan fisik } \\
-\quad \text { Konflik pekerjaan } \\
-\quad \text { Role ambiguity } \\
\text { Variabel Terikat: } \\
-\quad \text { Burnout }\end{array}$ & $\begin{array}{l}\text { - Sress kerja berpengaruh positif signifikan } \\
\text { terhadap burnout }\end{array}$ \\
\hline
\end{tabular}

Sumber: Disarikan dari Berbagai Jurnal untuk Penelitian ini, 2020

Berdasarkan uraian di atas maka dikembangkan hipotesis berikut:

H3: $\quad$ Stress kerja berpengaruh positif terhadap burnout

\section{Metode Penelitian \\ Populasi dan Sampel \\ Populasi} Indonesia.

Populasi dan sekaligus sampel yang menjadi obyek penelitian yaitu pekerja pelaut

\section{Sampel}


Penentuan jumlah sampel untuk analisis Structural Equation Modeling menggunakan rumus (Ferdinand, 2015) adalah jumlah indikator x 5 sampai 10. Oleh karena jumlah indikator yang digunakan dalam studi ini berjumlah 13 maka jumlah sampel penelitian berada pada rentang 65 - 130. Selanjutnya Hair, dkk dalam Ferdinand (2005) bahwa ukuran yang sampel sesuai untuk SEM dengan pendekatan teknik estimasi Maximum Likelihood adalah antara 100 - 200 sampel. Dengan mengacu pada pendapat Hair maka jumlah sampel yang digunakan dalam studi ini adalah $100-130$ pekerja pelaut Indonesia.

\section{Teknik Pengambilan Sampel}

Pengambilan sampel dilakukan dengan menggunakan teknik non probability sampling dengan pendekatan purposive sampling atau judgmental. Pendekatan ini dipilih karena mempertimbangkan bahwa hanya responden dengan kriteria-kriteria tertentu yang memiliki informasi mengenai variabel yang diteliti dalam studi ini. Kriteria responden ditentukan dengan menggunakan pendekatan inklusi-eksklusi yang sesuai dengan tujuan yang hendak dicapai dalam studi ini, yaitu:

1. Responden adalah pekerja pelaut berwarganegara Indonesia

2. Responden bekerja pada kapal berbendera Indonesia maupun asing

3. Responden telah bekerja sebagai pelaut minimal 3 tahun

\section{Pengembangan Indikator Variabel Penelitian}

\section{Variabel Beban Kerja}

Pengukuran beban kerja dilakukan dengan menggunakan empat indicator yang meliputi: Jumlah pekerjaan (X1), Target kerja (X2), Kelebihan beban (X3), dan Tekanan kerja (X4).

Tabel 5. Pengembangan Pengukuran Variabel Beban Kerja

\begin{tabular}{cll}
\hline Variabel & \multicolumn{1}{c}{ Indikator } \\
\hline Beban Kerja & X1: & Jumlah pekerjaan \\
& X2: & Target kerja \\
& X3: & Kelebihan beban \\
& X4: & Tekanan kerja \\
& Sumber: Gibson (2019), Utomo (2008) \\
\hline
\end{tabular}

Sumber: Disarikan dari Permendagri No. 12/2008, Utomo (2008), Gibson (2019), Utomo (2008) untuk Penelitian ini, 2020

\section{Variabel Stress Kerja}

Pengukuran variabel stress kerja dilakukan dengan menggunakan lima indicator yang mencakup: Resah / gelisah (X5), Mudah marah (X6), Mudah lelah (X7), Tidak focus (X8), Banyak melakukan kesalahan (X9).

Tabel 6. Pengembangan Pengukuran Variabel Stress Kerja

\begin{tabular}{cll}
\hline \multicolumn{1}{c}{ Variabel } & & \multicolumn{1}{c}{ Indikator } \\
\hline Stress Kerja & X5: & Resah / gelisah \\
& X6: & Mudah marah \\
& X7: & Mudah lelah \\
& X8: & Tidak focus \\
\hline
\end{tabular}


Sumber: Sunyoto (2013)

Sumber: $\quad$ Disarikan dari Salleh, Bakar dan Keong (2008), Sunyoto (2013) untuk Penelitian ini, 2020

\section{Variabel Burnout}

Pengukuran burnout dilakukan dengan menggunakan indicator-indikator yang diadopsi dari penelitian yang dilakukan oleh George (2005) dalam Efa (2011); Almaududi (2019) yang mencakup empat indicator, yaitu: Kelelahan fisik (X10), Kelelahan mental (X11), Kelelahan emosional (X12), Penghargaan diri yang rendah (X13).

Tabel 7. Pengembangan Pengukuran Variabel Burnout

\begin{tabular}{lll}
\hline \multicolumn{1}{c}{ Variabel } & \multicolumn{1}{c}{ Indikator } \\
\hline Burnout & X10: & Kelelahan fisik \\
X11: & Kelelahan mental \\
X12: & Kelelahan emosional \\
X13: & Penghargaan diri yang rendah \\
Sumber: George (2005), Efa (2011) \\
\hline Disarikan dari \\
Petyawati dalam Widanti (2010), George (2005), Efa (2011) untuk
\end{tabular}

\section{Teknik Pengumpulan Data}

Pengumpulan data dilakukan melalui wawancara dengan menggunakan kuisioner. Penentuan skoring untuk jawaban yang diberikan responden untuk data primer digunakan skala interval 1-10. Pengukuran ini menggunakan beberapa pertanyaan yang menggambarkan kondisi yang dialami atau dilakukan responden. Interval jawaban tersebut meliputi variasi dengan interpretasi ; sangat tidak setuju yang diwakili nilai 1 (satu) sampai dengan sangat setuju yang diwakili oleh nilai 10 (sepuluh).

\section{Teknik Analisis Data}

Pengujian model empiris dan kausalitas atau pengaruh antar variabel dilakukan dengan pendekatan analisa SEM (Structural Equation Modelling) yang dijalankan dengan program AMOS (Analisis Moment Structure).

\section{Hasil dan Pembahasan}

Studi ini merupakan kajian empiris untuk menguji pengaruh beban kerja dan stress kerja dalam menjelaskan terjadinya burnout pada pekerja pelaut. Variabel beban kerja, stress kerja dan burnout yang diteliti dalam penelitian ini merupakan variabel latent yang pengukurannya tidak dapat dilakukan secara langsung. Untuk dapat mengukur beban kerja, stress kerja dan burnout dilakukan dengan menggunakan indicator. Indicator yang menjadi alat ukur diadopsi dan dikembangkan dari penelitian-penelitian terdahulu yang relevan dengan variabel yang diteliti. Oleh karena itu, untuk memastikan ketepatan alat ukur dan konsistensi hasil pengukuran perlu dilakukan terhadap indicator-indikator tersebut. Pengujian ketepatan alat ukur dan konsistensi hasil pengukuran dilakukan dengan pendekatan confirmatory analysis sehingga akan dapat diketahui indicator-indikator yang tepat dan mampu menghasilkan pengukuran yang konsisten. Setelah melalui pengujian konfirmatori, analisis dilanjutkan dengan uji persyaratan, uji kelayakan model dan terakhir adalah uji hipotesis yang merupakan pengujian pengaruh antara variabel. Keseluruhan proses analisis data tersebut diuraikan berikut ini.

\section{Analisis Konfirmatori}


Analisis faktor konfirmatori merupakan tahap pengukuran terhadap indikator-indikator yang membentuk variabel laten dalam model penelitian. Analisis faktor konfirmatori dari masingmasing variabel dilakukan dengan menganalisis nilai standardized regression weight serta nilai variance extracted dan reliability contruct.

\section{Analisis Standardized Regression Weight}

Analisis standardized regression weight dilakukan untuk mengetahui tepat atau tidaknya sebuah indicator dalam merefleksikan variabel yang diukur yang dilakukan dengan kriteria pengujian sebagai berikut:

a. Jika diketahui nilai standardized regression weight $>0,6$ dengan nilai signiifkansi < 0,05 maka dapat diartikan bahwa indicator yang digunakan merupakan indicator yang tepat dalam merefleksikan variabel yang diukur.

b. Jika diketahui nilai standardized regression weight $<0,6$ dengan nilai signiifkansi $>$ 0,05 maka dapat diartikan bahwa indicator tidak mampu merefleksikan variabel yang diukur.

Tabel 8. Nilai Standardized Regression Weight Indikator pada Variabel Penelitian

\begin{tabular}{|c|c|c|c|c|c|c|c|}
\hline & & & Std Estimate & Estimate & S.E. & C.R. & $\mathrm{P}$ \\
\hline $\mathrm{X} 1$ & $<---$ & Beban_Kerja &, 770 & 1,000 & & & \\
\hline $\mathrm{X} 2$ & $<--$ & Beban_Kerja & ,807 & 1,141 & ,133 & 8,554 & $* * *$ \\
\hline $\mathrm{X} 3$ & $<---$ & Beban_Kerja &, 850 & 1,238 &, 135 & 9,141 & $* * *$ \\
\hline $\mathrm{X} 4$ & $<---$ & Beban_Kerja & ,821 & 1,179 &, 135 & 8,754 & $* * *$ \\
\hline $\mathrm{X} 5$ & $<---$ & Stress_Kerja & ,787 & 1,000 & & & \\
\hline X6 & $<---$ & Stress_Kerja & ,742 & 1,008 &, 124 & 8,109 & $* * *$ \\
\hline $\mathrm{X} 7$ & $<---$ & Stress_Kerja & ,860 & 1,125 & ,116 & 9,698 & $* * *$ \\
\hline $\mathrm{X} 8$ & $<---$ & Stress_Kerja &, 782 & 1,002 &, 115 & 8,678 & $* * *$ \\
\hline $\mathrm{X} 9$ & $<--$ & Stress_Kerja & ,810 & ,958 &, 105 & 9,094 & $* * *$ \\
\hline $\mathrm{X} 10$ & $<---$ & Burnout & ,900 & 1,000 & & & \\
\hline X11 & $<--$ & Burnout & ,904 & 1,159 & ,079 & 14,722 & $* * *$ \\
\hline $\mathrm{X} 12$ & $<---$ & Burnout & ,901 & 1,079 & ,074 & 14,498 & $* * *$ \\
\hline $\mathrm{X} 13$ & $<---$ & Burnout & ,920 & 1,142 & 074 & 15,526 & $* * *$ \\
\hline
\end{tabular}

Sumber: Data primer yang diolah, 2020

Dari hasil analisis faktor konfirmatori pada variabel beban kerja, stress kerja dan burnout diperoleh bahwa nilai pengujian pada masing-masing faktor pembentuk suatu konstruk menunjukkan bahwa seluruh indikator telah memiliki nilai standardized regression weight $>0,6$ dan dengan signifikansi $<0,05$. Berdasarkan hasil statistik tersebut dapat disimpulkan bahwa masing-masing indicator yang diadopsi dalam studi ini merupakan indicator yang tepat untuk dapat merefleksikan variabel yang diukur.

\section{Reliability Construct dan Variance Extracted}

Uji reliabilitas menunjukkan sejauh mana suatu alat ukur dapat memberikan hasil yang relative sama apabila dilakukan pengukuran kembali pada obyek yang sama. Nilai reliabilitas minimum dan dimensi/indicator pembentuk variable laten yang dapat diterima adalah sebesar 0,70. Sedangkan pengukuran Variance Extract menunjukkan jumlah varians dari indicator yang diekstraksi oleh konstruk/variable laten yang dikembangkan. Nilai Variance Extract yang dapat diterima adalah minimal 0,50. Hasil perhitungan Reliability Construct dan Variance Extracted dapat dilihat pada table berikut.

Tabel 9. Reliability Construct dan Variance Extracted

\begin{tabular}{lccc}
\hline & Variabel & Reliabilitas & Variance \\
\hline Beban kerja & 0,949 & 0,823
\end{tabular}




\begin{tabular}{lrr} 
Stress kerja & 0,938 & 0,752 \\
Burnout & 0,989 & 0,959 \\
\hline
\end{tabular}

Sumber: Data Primer yang Diolah, 2020

Berdasarkan hasil perhitungan yang ditampilkan dalam diatas diketahui bahwa seluruh variabel laten dapat memenuhi kriteria Reliability Construct dan Variance Extract. Sehingga dapat disimpulkan bahwa indikator-indikator yang diamati dapat mencerminkan faktor yang dianalisis dan secara bersama-sama mampu mencerminkan adanya sebuah unidimensionalitas.

\section{Pengujian Asumsi SEM}

\section{Evaluasi Normalitas Data}

Estimasi dengan Maximum Likelihood menghendaki variable observed harus memenuhi asumsi normalitas multivariate. Analisa normalitas dilakukan dengan mengamati nilai CR untuk multivariate dengan rentang \pm 2.58 pada tingkat signifikansi 1\% (Ghozali, 2004).

Tabel 10. Hasil Pengujian Normalitas Data

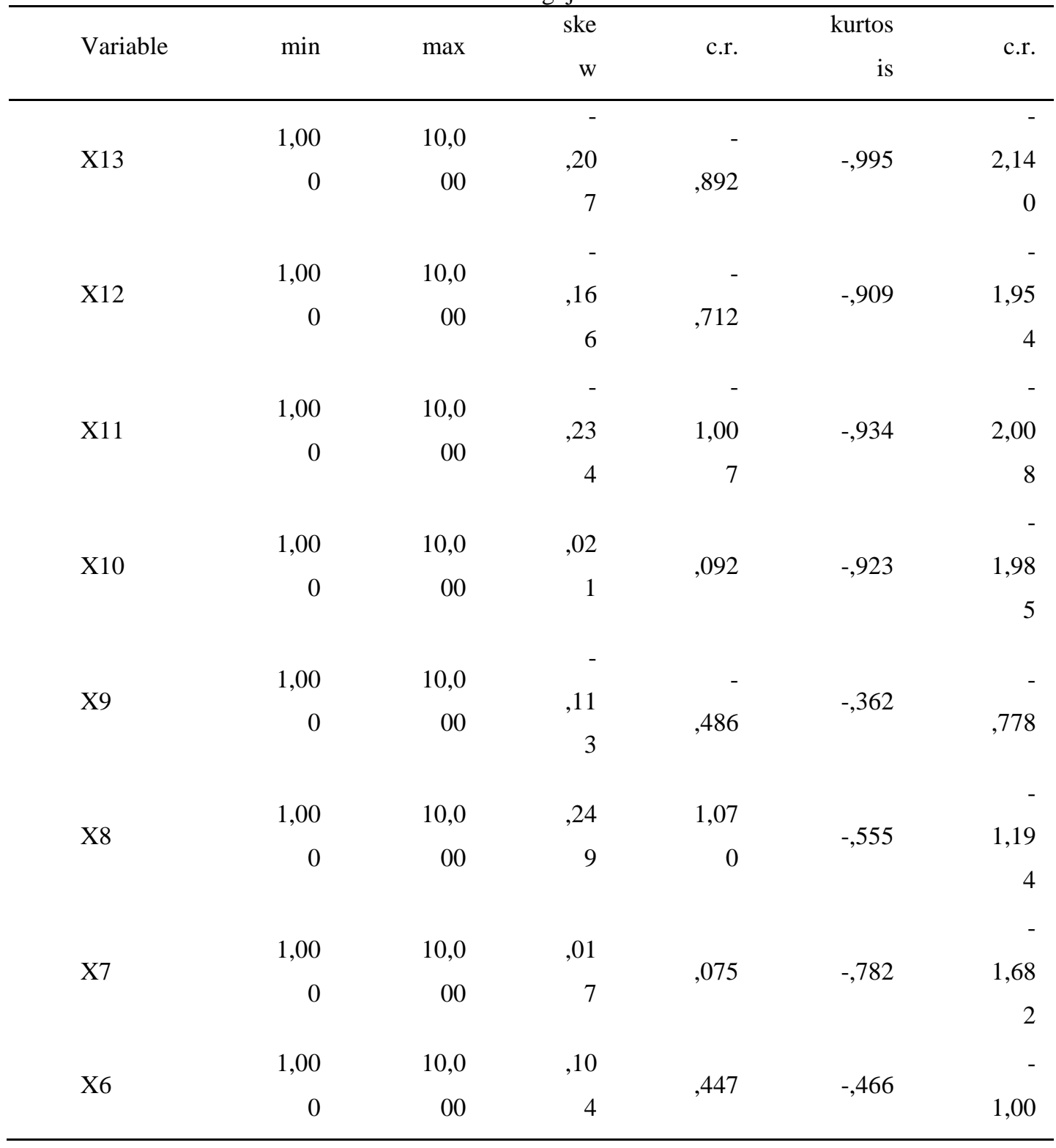




\begin{tabular}{lrrrrrr}
\hline Variable & min & max & $\begin{array}{r}\text { ske } \\
\text { w }\end{array}$ & c.r. & $\begin{array}{r}\text { kurtos } \\
\text { is }\end{array}$ & c.r. \\
\hline & & & & & & 2 \\
X5 & 1,00 & 10,0 &, 04 &, 186 &,- 354 &, 762 \\
& 0 & 00 & 3 & & & \\
X4 & 1,00 & 10,0 &, 61 & 2,64 &, 222 &, 477 \\
& 0 & 00 & 4 & 2 & & - \\
X3 & 1,00 & 10,0 &, 41 & 1,77 &,- 535 & 1,15 \\
& 0 & 00 & 3 & 8 & & 0 \\
X2 & 1,00 & 10,0 &, 25 & 1,07 & &,- 358 \\
X1 & 0 & 00 & 0 & 4 & &, 770 \\
Multivari & 1,00 & 10,0 &, 47 & 2,02 &,- 338 &, 726 \\
ate & 0 & 00 & 0 & 2 & &, 851 \\
\hline
\end{tabular}

Sumber : Data prime yang diolah, 2020

Hasil pengujian normalitas menunjukkan bahwa nilai CR untuk multivariate adalah 0,851 yang berada di bawah 2,58, sehingga dapat dikatakan tidak terdapat bukti bahwa distribusi data variable observed tidak normal.

\section{Evaluasi Outliers}

Outliers adalah observasi atau data yang memiliki karakteristik unik yang terlihat sangat berbeda dengan data lainnya dan muncul dalam bentuk nilai ekstrim, baik untuk variable tunggal maupun kombinasi (Hair, et al, 1995, p.57). Uji Jarak Mahalanobis (Mahalanobis Distance) digunakan untuk melihat ada tidaknya outliers secara multivariate. Evaluasi outliers dilakukan dengan menganalisis nilai Chi Square table dengan nilai Mahalanobis Distance. Untuk menghitung Mahalanobis Distance berdasarkan nilai Chi-Square pada derajat bebas 13 (jumlah indikator) pada tingkat $\mathrm{p}<0,001$ adalah $\chi^{2}(13 ; 0,001)=34,528$ (berdasarkan tabel distribusi $\chi^{2}$ ). Sedangkan nilai Mahalanobis Distance yang dihasilkan dari pengujian model penelitian adalah:

Tabel 11. Nilai Mahalanobis Distance

\begin{tabular}{rrrr}
\hline Observation number & Mahalanobis d-squared & $\mathrm{p} 1$ & $\mathrm{p} 2$ \\
\hline 70 & 29,146 &, 006 &, 501 \\
37 & 25,641 &, 019 &, 625 \\
98 & 25,603 &, 019 &, 359 \\
4 & 24,199 &, 029 &, 411 \\
25 & 22,668 &, 046 &, 579 \\
\hline
\end{tabular}

Sumber : Data prime yang diolah, 2020

Berdasarkan hasil pengolahan data dapat diketahui bahwa jarak Mahalanobis maksimal adalah 29,146 yang lebih kecil dari $\chi^{2}$ tabel sebesar 34,528 yang berarti bahwa tidak terdapat 
multivariate outliers sehingga dapat disimpulkan bahwa tidak terdapat masalah outliers pada data penelitian.

\section{Evaluasi Nilai Residual}

Setelah melakukan estimasi, residualnya haruslah kecil atau mendekati nol dan distribusi frekuensi dari kovarians residual haruslah bersifat simetrik. Jika suatu model memiliki nilai kovararians residual yang tinggi (> 2,58) maka sebuah modifikasi perlu dipertimbangkan dengan catatan ada landasan teoritisnya. Dari hasil analisis statistik yang dilakukan dalam penelitian ini, tidak ditemukan satu nilai standardized residual kovarians yang lebih dari 2.58 sehingga dapat disimpulkan bahwa syarat residual terpenuhi.

\section{Pengujian Kelayakan Model Penelitian}

Setelah dilakukan analisis terhadap tingkat unidimensionalitas dari dimensidimensi/indikator-indikator pembentuk variabel laten yangdiuji dengan confirmatory factor analysis analisis selanjutnya adalah analisis Structural Equal Modeling (SEM) secara full model. Adapun hasil pengolahan data untuk analisis full model SEM dijelaskan di bawah ini.

\section{Gambar 1. Pengujian Model Penelitian}

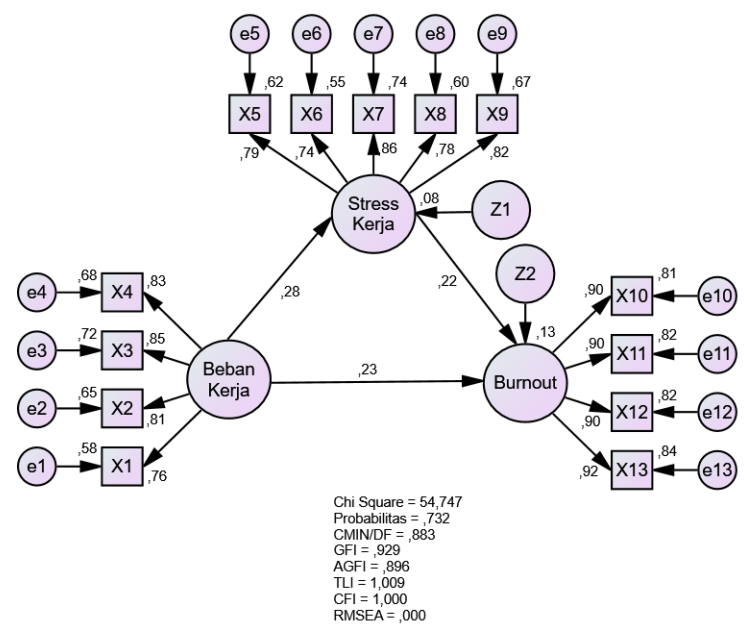

Sumber : Data primer yang diolah, 2020

Tahap pertama dalam pengujian model penelitian adalah melakukan analisis kelayakan model penelitian. Adapun hasil pengujian kelayakan pada model penelitian yang dikembangkan dalam penelitian ini, disajikan dalam Tabel berikut ini.

Tabel 12. Hasil Pengujian Kelayakan Model Penelitian

\begin{tabular}{lccc}
\hline \multicolumn{1}{c}{ Goodness of Fit Indeks } & Cut off Value & Hasil & Evaluasi Model \\
\hline Chi-Square $(\mathrm{df}=62)$ & $<81,381$ & 54,747 & Baik \\
Probability & $\geq 0,05$ & 0,732 & Baik \\
CMIN/DF & $\leq 2,00$ & 0,883 & Baik \\
GFI & $\geq 0,90$ & 0,929 & Baik \\
AGFI & $\geq 0,90$ & 0,896 & Marginal \\
TLI & $\geq 0,95$ & 1,009 & Baik \\
CFI & $\geq 0,95$ & 1,000 & Baik \\
RMSEA & $\leq 0,08$ & 0,000 & Baik \\
\hline
\end{tabular}


Sumber: Data primer yang diolah, 2020

Berdasarkan hasil pengujian kelayakan model yang disajikan dalam Tabel di atas menunjukkan bahwa secara keseluruhan kriteria pengujian dalam kategori baik atau memenuhi kriteria penilaian yang dipersyaratkan. Pada uji Chi-Square, sebuah model akan dianggap baik jika hasilnya menunjukkan nilai Chi-Square hitung yang lebih kecil dari nilai Chi-Square tabel. Semakin Chi-Square hitung yang lebih kecil dari nilai Chi-quare tabel menunjukkan bahwa semakin baik model tersebut berarti tidak ada perbedaan antara estimasi populasi dengan sampel yang diuji. Model penelitian ini menunjukkan bahwa nilai Chi-Square hitung adalah 54,747 sedangkan nilaikritis/tabel Chi-Square dengan df $=62$ adalah 81,381. Oleh karena nilai ChiSquare hitung dalam penelitian ini lebih kecil dari nilai kritis/tabelnya ini berarti bahwa model penelitian ini tidak berbeda dengan populasi yang diestimasi/model dianggap baik (diterima).

\section{Pengujian Hipotesis}

Seteleh melakukan penilaian terhadap asumsi-asumsi yang ada pada SEM, selanjutnya akan dilakukan pengujian hipotesis sebagaimana diajukan pada bab terdahulu. Pengujian keempat hipotesis yang diajukan dalam penelitian ini dilakukan dengan menganalisis nilai Critical Ratio (CR) dan probabilitas dari suatu hubungan kausalitas.

Tabel 13. Pengujian Hipotesis

\begin{tabular}{lllrrrrr}
\hline & & & Std Estimate & Estimate & S.E. & C.R. & P \\
\hline Stress_Kerja & $<---$ & Beban_Kerja &, 279 &, 315 &, 123 & 2,561 &, 010 \\
Burnout & $<---$ & Stress_Kerja &, 221 &, 244 &, 115 & 2,121 &, 034 \\
Burnout & $<---$ & Beban_Kerja &, 232 &, 289 &, 131 & 2,208 &, 027 \\
\hline
\end{tabular}

Sumber: Data primer yang diolah, 2020

\section{Pengujian Pengaruh Beban Kerja terhadap Stress Kerja}

Parameter estimasi untuk pengujian pengaruh beban kerja terhadap stress kerja dihasilkan nilai standardized estimate yang menunjukkan besarnya pengaruh beban kerja terhadap stress kerja sebesar 0,279 dengan nilai CR sebesar 2,561 dan probabilitas sebesar 0,010. Oleh karena nilai probabilitas < 0,05 maka dapat disimpulkan bahwa pengaruh beban kerja terhadap stress kerja secara statistik terbukti berpengaruh positif signifikan. Artinya, jika beban kerja yang dialami oleh responden meningkat maka hal ini akan mengakibatkan meningkatkan stress kerja pada pelaut.

\section{Pengujian Pengaruh Beban Kerja terhadap Burnout}

Parameter estimasi untuk pengujian pengaruh beban kerja terhadap burnout dihasilkan nilai standardized estimate yang menunjukkan besarnya pengaruh beban kerja terhadap burnout sebesar 0,232 dengan nilai CR sebesar 2,208 dan probabilitas sebesar 0,027. Oleh karena nilai probabilitas < 0,05 maka dapat disimpulkan bahwa pengaruh beban kerja terhadap burnout secara statistik terbukti berpengaruh positif signifikan. Artinya, jika beban kerja yang dialami oleh responden meningkat maka hal ini akan mengakibatkan meningkatkan burnout pada pelaut.

\section{Pengujian Pengaruh Stress Kerja terhadap Burnout}

Parameter estimasi untuk pengujian pengaruh stress kerja terhadap burnout dihasilkan nilai standardized estimate yang menunjukkan besarnya pengaruh stress kerja terhadap burnout sebesar 0,221 dengan nilai CR sebesar 2,121 dan probabilitas sebesar 0,034. Oleh karena nilai probabilitas < 0,05 maka dapat disimpulkan bahwa pengaruh stress kerja terhadap burnout secara statistik terbukti berpengaruh positif signifikan. Artinya, jika stress kerja yang dialami oleh responden meningkat maka hal ini akan mengakibatkan meningkatkan burnout pada pelaut.

\section{Pembahasan}

\section{Pengaruh Beban Kerja terhadap Stress Kerja}

Ketika karyawan bekerja pada suatu perusahaan maka karyawan tersebut akan melakukan serangkaian tanggung jawab pekerjaan sesuai dengan job description dan jabatan yang di 
embannya. Seringkali pekerjaan yang dilakukan tersebut melebihi apa yang sudah tertera dalam job descriptionnya yang kemudian direspon sebagai beban kerja. Beban kerja yang terus menerus yang dialami karyawan ini akan menimbulkan stress kerja. Hasil studi empiris pada variabel beban kerja dan stress kerja yang dilakukan dalam studi ini menunjukkan bahwa secara statistik, beban kerja terbukti berpengaruh positif signifikan terhadap stress kerja. Artinya, jika beban kerja yang diterima oleh pekerja pelaut meningkat maka hal ini akan menyebabkan terjadinya peningkatan stress kerja. Hasil studi ini memperkuat hasil-hasil penelitian sebelumnya yang telah mendahului menguji pengaruh kedua variabel ini, yaitu Yo dan Surya (2015), Kusuma dan Soesatyo (2014), Hatmawan (2015), Rizky dan Afrianty (2018) dimana pada penelitian tersebut juga menunjukkan bahwa beban kerja berpengaruh positif signifikan terhadap stress kerja.

\section{Pengaruh Beban Kerja terhadap Burnout}

Burnout dapat disebabkan oleh faktor internal dan eksternal (Baron dan Greenberg, 1993). Faktor eksternal merupakan kondisi kerja, yang meliputi lingkungan kerja psikologis yang kurang baik, kurangnya kesempatan untuk promosi, imbalan yang diberikan tidak mencukupi, kurangnya dukungan sosial dari atasan, tuntutan pekerjaan, pekerjaan yang monoton, dan (2) Faktor internal meliputi usia, jenis kelamin, harga diri, tingkat pendidikan, masa kerja dan karakteristik kepribadian. Jadi beban kerja yang diteliti dalam penelitian ini adalah faktor eksternal yang berasal dari kondisi kerja yang dapat menimbulkan burnout pada pegawai. Beban kerja terjadi karena seseorang karyawan mempunyai terlalu banyak pekerjaan yang harus dikerjakan dibawah tekanan jadwal waktu yang sangat ketat dan tidak sesuai dengan kemampuan (Bolino dan Turnley, 2005). Ketika terlalu banyak pekerjaan yang harus dikerjakan menyebabkan kelelahan fisik dan mental, bahkan kejenuhan dan stres akibat beban pekerjaan, ditambah lagi dengan perasaan bahwa keahlian yang dimiliki tidak memenuhi tuntutan tugas, hal tersebut yang nantinya akan memicu burnout.

Pengujian pengaruh variabel beban kerja terhadap burnout dengan menggunakan data empiris yang telah dilakukan dalam studi ini menunjukkan bahwa secara statistik, bebab kerja terbukti berpengaruh positif signifikan terhadap burnout. Artinya, jika pekerja pelaut mengalami peningkatan beban kerja maka hal ini akan menyebabkan meningkatnya burnout. Hasil studi ini sejalan dengan penelitian yang dilakukan oleh Atmaja dan Suana (2019), Romadhoni dan Suryatni (2015), Pradana, Kristanto dan Hidayat (2017), Hardiani (2020) yang juga menunjukkan adanya pengaruh positif beban kerja terhadap burnout.

\section{Pengaruh Stress Kerja terhadap Burnout}

Hardiyanti (2013) menyatakan bahwa burnout merupakan epidemi yang melanda dunia kerja, memperlihatkan bagaimana kondisi emosional individu yang merasa letih serta jenuh secara mental dikarenakan tuntutan dan tekanan pekerjaan yang tinggi. Burnout merupakan bagian dari stres (Luthans, 2005). Burnout merupakan kelelahan fisik, mental, dan emosional yang terjadi karena stres yang diderita dalam jangka waktu yang lama dan melibatkan emosional yang tinggi (Rosyid, 1996). Kreitner dan Kinicki (1992) menyatakan bahwa burnout merupakan akibat dari stres yang dialami individu dalam jangka waktu yang lama dan dengan intensitas yang cukup sering, ditandai dengan kelelahan fisik, mental, dan emosional, serta rendahnya pengahargaan terhadap diri sendiri yang mengakibatkan individu merasa terpisah dari lingkungannya. King et al (1995) juga menyatakan bahwa stres pada individu di tempat kerja yang berlangsung secara terus menerus akan menyebabkan kelelahan emosional dan motivasi rendah sehingga akan mempengaruhi timbulnya burnout.

Keterpengaruhan stress kerja terhadap burnout yang dianalisis dalam studi ini dengan menggunakan data empiris menunjukkan bahwa secara statistik, stress kerja terbukti berpengaruh positif signifikan terhadap burnout. Artinya, terjadinya peningkatan burnout yang dialami oleh pekerja pelaut disebabkan oleh terjadinya peningkatan stress kerja. Hasil penelitian ini memperkuat hasil-hasil penelitian sebelumnya dari Satriyo dan Survival (2014) dan Zeinalpour (2014) yang juga menunjukkan bahwa stress kerja berpengaruh positif signifikan terhadap burnout.

\section{Kesimpulan}


Burnout merupakan epidemi yang melanda dunia kerja, memperlihatkan bagaimana kondisi emosional individu yang merasa letih serta jenuh secara mental dikarenakan tuntutan dan tekanan pekerjaan yang tinggi. Burnout menyebabkan seseorang tidak memiliki tujuan dan tidak mampu memenuhi kebutuhan dalam bekerja. Pekerja yang mengalami burnout menjadi berkurang energi dan ketertarikannya pada pekerjaan. Bagi organisasi, burnout dapat mengakibatkan terjadinya peningkatan frekuensi tidak masuk kerja, berhenti dari pekerjaan atau job turnover, sehingga kemudian berpengaruh pada efektivitas dan efisiensi kerja dalam organisasi. Burnout juga dapat menimbulkan penurunan atau dan memburuknya performance karyawan, dan produktivitas yang rendah sehingga banyak menimbulkan conflict di dalam ruang lingkup seseorang dan keluarganya. Hasil studi ini menunjukkan bahwa terjadinya burnout disebabkan oleh stress kerja dan beban kerja. Oleh sebab itu, penting bagi organisasi untuk mengatur rangkaian job description dengan jabatan dan kompetensi agar tidak memicu terjadinya beban kerja yang kemudia dapat berdampak pada terjadinya stress kerja dan burnout.

\section{Daftar Pustaka}

Almaududi.S.(2019).Pengaruh Kejenuhan Kerja (Burnout) Terhadap Kinerja Karyawan Bagian Operator Di PT PLN (Persero) Unit Pelaksana Pengendalian Pembangkit Jambi Unit Layanan Pusat Listrik Payo Selincah. Journals Of Economics and Business. 3(2), 193-201

Arie Fajriani, Dovi Septiari. (2015). Pengaruh Beban Pekerjaan terhadap Kinerja Karyawan: Efek Mediasi Burnout. Jurnal Manajemen dan Kewirauhsaan. 1(2), 30-59

Atmaja, I Gede Indra Wira \& I Wayan Suana. (2019). Pengaruh Beban Kerja terhadap Burnout dengan Role Stress sebagai Variabel Mediasi pada Karyawan Rumpurs Restaurant. EJurnal Manajemen, 8 (2), 7775-7804.

Baron, A dan Jerald Greenberg. (1993). Behaviour in Organization, Understanding and Managing the Human side of Work. New Jersey: Prentice Hall Inc.

Bolino, Mark C dan William H Turnley. (2005). The Personal Costs of citeenship behaviour : The Relationsip Between Individual Initiative and Workload, Job Stress, and Work Family Conflict. Journal of Applied Pschology, 90 (4), 740-748

Dita, Puspitasari dan Handayani M Muryantinah. (2014). Hubungan Tingkat Self Efficacy Guru dengan Tingkat Burnout pada Guru Sekolah Inklusi di Surabaya. Jurnal Psikologi Pendidikan dan Perkembangan, 3(1).

Efa dkk. (2011). Hubungan antara Motivasi Kerja Perawat dengan Kecenderungan Mengalami Burnout pada Perawat di RSUD-Serui Papua. Surabaya. Fakultas Psikologi Universitas Hang-Tuah Surabaya

Eviaty \& Satiadarma M.P.( 2005) .Persepsi terhadap Dukungan Sosial Rekan Sekerja dan Gejala Burnout (Studi Pada Perawat Unit Perawatan Intensif). Jurnal Phronesis, 7(2), 102-118.

Dita Ayu Puspitasari dan Muryantinah Mulyo Handayani. (2014). Hubungan Tingkat SelfEfficacy Guru dengan Tingkat Burnout pada Guru Sekolah Inklusif di Surabaya. Jurnal Psikologi dan Pendidikan Pengembangan. 3(1): 59-68

Fajriani, Arie \& Dovi Septiari. (2015). Pengaruh Beban Pekerjaan terhadap Kinerja Karyawan: Efek Mediasi Burnout. Jurnal Akuntansi, Ekonomi dan Manajemen Bisnis, 3 (1), 74-79.

Ferdinand, Augusty. (2015). Metode Penelitian Manajemen. Semarang: BP Undip.

Fillhumaam, Faaris Muhammad., Gartinia Nurcholis \& Rini Nurahaju. (2019). Hubungan Stres Kerja dan Kepribadian dengan Burnout Pada Anak Buah Kapal (ABK) KRI "X" TNI Angkatan Laut Surabaya. Jurnal Sains Psikologi, 8(2), 199-207. 
George, Terry. (2005). Dasar-Dasar Manajemen. Jakarta: PT. Bumi Aksara.

Gibson, James L. (2019). Perilaku Organisasi. Jakarta: Penerbit Erlangga.

Greenhaus, J.H \& N.J Beutell. (2005). Sources of Conflict between Work and Family Roles. Academy of Management, 10, 76-88.

Hair J.F. et.al (1995), Multivariate Data Analysis With Reading, Fourth Edition, Prentice Hall. New Jersey

Hardiani, Wenefrida Ardhian Ayu. (2020). Pengaruh Work Family Conflict Dan Beban Kerja Terhadap Burnout dan Dampaknya Pada Cyberloafing (Studi Pada PT PLN (Persero) Pusat Manajemen Konstruksi). Jurnal Visi Manajemen. 5 (1). 651-668.

Hardiyanti, R. (2013). Burnout Ditinjau dari Big Five Factors Personality pada Karyawan Kantor Pos Pusat Malang. Jurnal Psikologi Universitas Muhammadiyah

Hatmawan, Aglis Andhita. (2015). Pengaruh Konflik Kerja, Beban Kerja serta Lingkungan Kerja terhadap Stress Pegawai PT. PLN (Persero) Area Madiun Rayon Magetan. ASSETS: Jurnal Akuntansi dan Pendidikan, 4 (1), 91-98.

Hera, Rasyidin \& Hasmin. (2016). Pengaruh Konflik Peran Ganda, Beban Kerja dan Kelelahan Kerja (Burnout) dengan Kinerja Perawat Wanita di RSUD I Lagaligo Kabupaten Luwu Timur. Jurnal Mirai Management. 1 (1). 119-135.

Ibrahim, Isra' Dewi Kuntary., Thatok Asmony \& Siti Nurmayanti. (2017). Pengaruh Stress Kerja terhadap Turnover Intention yang Dimediasi oleh Burnout (Studi pada Karyawan Hotel Bintang Empat di Kota Mataram. Jurnal Magister Manajemen Universitas Mataram.

Indilusiantari, Vera \& Inggit Meliana A. (2015). Faktor-Faktor Yang Berhubungan Dengan Burnout Syndrome Pada Pegawai Di Direktorat Bina Kesehatan Kerja Dan Olahraga Kementerian Kesehatan Republik Indonesia Jakarta Selatan Tahun 2015. Jurnal Ilmiah Kesehatan, 7 (1), 28-33.

King, L., D. King, G. Leskin, dan D. Foy. (1995). The Los Angeles Symptom Checklist: A SelfReport Measure of Posttraumatic Stress Disorder. Assessment, 2, 1-17.

Kreitner, R., Kinicki, A. (2010). Organizational Behavior (2nd ed.) Boston: Richard, D. Irwin, Inc.

Kusuma, Aster Andriani dan Yoyok Soesatyo. (2014). Pengaruh Beban Kerja dan Stress Kerja terhadap Kinerja Karyawan di PT PLN (Persero), 1 (4), 67-73.

Leither, M. \& Maslach, C. (2005), Vanishing Burnout : Six Strategies For Improving Your Relationship With Work, United States of America : Jossey-Bass

Luthans, Fred. (2005). Organizational Behavior: An Evidence - Based Approach. The McGraw Hill Companies. New York.

Melati Purbaningrat, I Putu., Ketut Surya Ida Bagus., (2015). Pengaruh beban kerja terhadap kepuasan kerja dengan stres kerja sebagai variabel mediasi. Jurnal Manajemen Unud, 4(5), 1149-1165.

Nafs, Tazkiatun. (2020). Pengaruh Beban Kerja terhadap Stres Kerja pada Guru Tahfidz di Pesantren Terpadu Darul Qur'an Mulia. Acta Psychologia, 2(2), 199-208. 
Permendagri No. 12 tahun 2008 tentang Pedoman Analisis Beban Kerja di Lingkungan Departemen Dalam Negeri dan Pemerintah Daerah.

Pradana, Bimba Ario., Rudi Suryo Kristanto \& Dwi Suryanto Hidayat. (2017). Pengaruh Lingkungan Kerja dan Beban Kerja terhadap Burnout pada Perawat RSUD Kardinah Kota Tegal. Jurnal Magisma, 5 (2), 61-70.

Prijayanti, Isnia. (2015). Pengaruh Beban Kerja dan Dukungan Sosial Terhadap Burnout pada Karyawan PT X. Universitas Islam Negeri Syarif Hidayatullah.

Rajan Selvarajan, Barjinder Singh, Peggy A. Cloninger. (2015). Role of personality and affect on the social support and work family conflict relationship. Journal of Vocational Behavior, 9(4), 39-56

Rizky, Denizia \& Tri Wulida Afrianty. (2018). Pengaruh Beban Kerja terhadap Stress Kerja dengan Work Life Balance sebagai Variabel Intervening (Studi pada Dinas Sosial Provinsi Jawa Timur Surabaya). Jurnal Administrasi Bisnis (JAB), 61 (4), 47-53.

Roboth. J. Y. (2015). Analisis Work Family Conflict, Stres Kerja Dan Kinerja Wanita Berperan Ganda Pada Yayasan Compassion East Indonesia. Jurnal Riset Bisnis dan Manajemen, 3(1), 33-46

Romadhoni, Lalu Ciptadi., Thatok Asmony \& Mukmin Suryatni. (2015). Pengaruh Beban Kerja, Lingkungan Kerja dan Dukungan Sosial terhadap Burnout Pustakawan di Kota Mataram. Khizanah Al-Hikmah. 3 (2). 125-145.

Rosyid, H.F. (1996). Burnout: Penghambat Produktivitas Yang Perlu Dicermati. Bulletin Psikologi, IV (1), 19-25.

Salleh, A.L., R.A Bakar dan W.K Keong. (2008). How Detrimental is Job Stress? : A Case Study Of Executives in the Malaysian Furniture Industry. International Review of Business Research Papers, 4 (5).

Satriyo, Moch \& Survival. (2014). Stress Kerja terhadap Burnout Serta Implikasinya pada Kinerja (Studi terhadap Dosen pada Universitas Widyagama Malang). Jurnal Manajemen dan Akuntansi, 3 (2), 52-63.

Sijabat, R. (2020). Gender Difference On The Modeling Of Turnover Intention Behavior. Fokus Ekonomi : Jurnal Ilmiah Ekonomi. https://doi.org/10.34152/fe.15.1.167-182

Sunyoto, Danang (2013). Dasar-Dasar Manajemen Pemasaran. Jakarta: Pranada Media Group.

Syed, Bashir. (2014). Perceived Organizational Support and The Cross-Cultural in The UAE, Education. Business, and Society : Contemporary Middle East Issues, 5 (1), 63-82

Utomo, T.W.W. (2008). Analisis Beban Kerja dalam Rangka Analisis Kebutuhan Pegawai. Tenggarong.

Virick, M., J. Lilly dan W. Casper. (2007). Doing More With Less: An Analysis of Work Life Balance Among Layoff Survivors. Journal of Career Development International. 12 (5).

Widanti, N.S. (2010). Tingkat Burnout Perawat di Rumah Sakit "X" Surabaya (tidak diterbitkan). FakultasPsikologi Universitas Hang Tuah Surabaya. Surabaya. 
Yo, Putu Melati Purbaningrat dan Ida Bagus Ketut Surya. (2015). Pengaruh Beban Kerja terhadap Kepuasan Kerja dengan Stress Kerja sebagai Variabel Mediasi. E-Jurnal Manajemen Unud, $4(5), 1149-1165$

Zeinalpour, Hamid., Mohammad Rasouli Dizaji, Haleh Ezza Tirad, Sadegh Babaeiheravai dan Babak Kashefi Mehr. (2014). Determining the Effect of Job Stress on Burnout Among The Employees. 